\title{
Thrombocytopenia in the Course of COVID-19 Infection
}

\author{
Noel Lorenzo-Villalba ${ }^{1}$, Abrar-Ahmad Zulfiqar ${ }^{1}$, Marc Auburtin², Marie Helene Schuhmacher², \\ Alain Meyer ${ }^{3}$, Yasmine Maouche ${ }^{1}$, Olivier Keller ${ }^{4}$, Emmanuel Andres ${ }^{1}$ \\ ${ }^{1}$ Service de Médecine Interne, Diabète et Maladies Métaboliques, Hôpitaux Universitaires de Strasboug, Strasbourg France \\ ${ }^{2}$ Service de Médecine Interne, Centre Hospitalier d'Epinal, Epinal, France \\ ${ }^{3}$ Service de Rhumatologie, Hôpitaux Universitaires de Strasboug, Strasbourg, France \\ ${ }^{4}$ Service de Médecine Interne, Centre Hospitalier de Haguenau, Haguenau, France
}

\section{Doi: 10.12890/2020_001702-European Journal of Case Reports in Internal Medicine - @ EFIM 2020}

Received: 01/05/2020

Accepted: 05/05/2020

Published: 07/05/2020

How to cite this article: Lorenzo-Villalba N, Zulfiqar AA, Auburtin M, Schuhmacher MH, Meyer A, Maouche Y, Keller O, Andres E. Thrombocytopenia in the course of COVID-19 infection. EJCRIM 2020;7: doi:10.12890/2020_001702.

Conflicts of Interests: The Authors declare that there are no competing interests.

This article is licensed under a Commons Attribution Non-Commercial 4.0 License

\section{ABSTRACT}

We report three cases of severe thrombocytopenia during COVID-19 infection associated with either cutaneous purpura or mucosal bleeding. The initial investigations ruled out other causes of thrombocytopenia. Two of the patients were treated with intravenous immunoglobulins and eltrombopag, while the third recovered spontaneously. A good clinical and biological response was achieved in all patients leading to hospital discharge.

\section{LEARNING POINTS}

- Immune thrombocytopenia should be considered in COVID-19-infected patients presenting with thrombocytopenia.

- Coronavirus-related thrombocytopenia can be severe and life-threatening.

- Despite the severity of coronavirus-related immune thrombocytopenia, recovery may be spontaneous or achieved following immunoglobulin or platelet growth factor administration.

\section{KEYWORDS}

COVID-19, thrombocytopenia, immune thrombocytopenia, immunoglobulins, eltrombopag

\section{INTRODUCTION}

Many haematological abnormalities such as blood hypercoagulability, elevated D-dimer levels, PT and aPTT prolongation, severe thrombocytopenia and disseminated intravascular coagulation (DIC) have been reported during COVID-19 infection. Such patients are at high risk of deep venous thrombosis and pulmonary embolism but, conversely, life-threatening bleeding secondary to immune-mediated thrombocytopenia may also occur.

\section{CASE DESCRIPTIONS}

\section{Case 1}

A 66-year-old man was admitted to the internal medicine department for a 6-day history of fever, cough, diarrhoea and progressive shortness of breath. His medical history was relevant for hypertension, liver cirrhosis and type 2 diabetes. He is retired and lives alone.

Upon admission, the patient was febrile, his blood pressure was 195/95 mmHg, heart rate was 105 bmp and oxygen saturation was $93 \%$ on room air. He was alert and oriented. Facial and trunk erythema was noted. Heart sounds were regular without any rubs or murmurs. Breath sounds were globally diminished with rales in the left pulmonary field. 
Blood tests showed elevated C-reactive protein (CRP; $125 \mathrm{mg} / \mathrm{I})$, white cell count $\left(2.3 \times 10^{\%} / \mathrm{I}\right)$, lymphocytes $0.36 \times 10^{9} / \mathrm{l}$, haemoglobin $13.1 \mathrm{~g} /$ $\mathrm{dl}$ and platelets $\left(73 \times 10^{9} / \mathrm{l}\right)$. The glomerular filtration rate (GFR) was $82 \mathrm{ml} / \mathrm{min}$, serum creatinine was $86 \mu \mathrm{mol} / \mathrm{l}$, and serum sodium was 128 $\mathrm{mmol} / \mathrm{l}$. Liver function tests were within the normal range. Troponin was $9 \mathrm{ng} / \mathrm{l}$ and NT-BNP was $147 \mathrm{pg} / \mathrm{ml}$. Arterial blood gases (room air) revealed: $\mathrm{pH}:$ : 7.41, $\mathrm{pCO}_{2}: 31 \mathrm{mmHg}, \mathrm{pO}_{2}: 83 \mathrm{mmHg}$ and $\mathrm{HCO}_{3}: 23 \mathrm{mmol} / \mathrm{l}$. The RT-PCR assay on oropharyngeal swabs for SARS-CoV-2 was positive. The chest CT was compatible with severe COVID-19 infection-related pneumonia. On day 5 , the patient experienced epistaxis requiring posterior balloon catheter placement. Laboratory tests revealed the platelet count had dropped to $1 \times 10^{9} / \mathrm{I}$. Serology tests for $\mathrm{VIH}$, VHC, VHB and antinuclear antibodies were negative. This prompted an immunoglobulin infusion at a dose of $1 \mathrm{~g} / \mathrm{kg}$ which was discontinued owing to acute heart failure. Eltrombopag ( $50 \mathrm{mg}$ per day) was then initiated. On day 8 , the platelet count was $20 \times 10^{9} / \mathrm{l}$ and on day 13 it was $149 \times 10^{\%} / \mathrm{l}$. Eltrombopag was subsequently reduced to $25 \mathrm{mg}$ per day. No other haemorrhagic events were reported and the patient clinically improved, leading to oxygen supply discontinuation and hospital discharge on day 15.

\section{Case 2}

A 57-year-old woman was admitted to the internal medicine department for a 10-day history of fever, partially responding to treatment, dry cough, and progressive shortness of breath. Forty-eight hours before admission, she had experienced an episode of epistaxis preceding the development of cutaneous purpura on the lower extremities. Her medical history was relevant for hypertension, thyroidectomy and secondary hypoparathyroidism. She is a retired nurse but has been recently working in a local hospital. There was no alcohol or illicit drug consumption.

Upon admission, the patient's temperature was $37.7^{\circ} \mathrm{C}$, blood pressure was $120 / 70 \mathrm{mmHg}$, heart rate was 100 bmp and oxygen saturation was $92 \%$ on room air. Heart sounds were regular without any rubs or murmurs. Breath sounds were diminished in the left pulmonary base where rales were heard. A painless non-infiltrative petechial purpura on the lower limbs as well as intraoral haemorrhagic bubbles were noted.

Leucocytes were $5.5 \times 10^{9} / \mathrm{l}$, lymphocytes were $0.82 \times 10^{9} / \mathrm{l}$, haemoglobin was $12.8 \mathrm{~g} / \mathrm{dl}$, and platelets were $2 \times 10^{\%} / \mathrm{l}$. Liver tests showed minor cytolysis. Electrolytes, renal function tests, and prothrombin time were within the normal range. CRP was $44 \mathrm{mg} / \mathrm{l}$. Serology tests for HIV, VHB, VHC and antinuclear antibodies were negative. The RT-PCR assay on oropharyngeal swabs for SARS-CoV-2 was positive. The patient received an initial perfusion of intravenous immunoglobulin at a dose of $1 \mathrm{~g} / \mathrm{kg}$ and a second perfusion on day 5 together with an initial dose of eltrombopag of $25 \mathrm{mg}$ per day. The dose of eltrombopag was doubled on day 8 . The platelet count rose to $75 \times 10^{\circ} / \mathrm{l}$, cutaneous purpura progressively disappeared and no mucous haemorrhage was noted. The patient was discharged on day 14.

Case 3

A 79-year-old man was admitted to the internal medicine department for a 7-day history of dry cough, confusion and falls 48 hours prior to admission. His medical history was relevant for hypertension and a previous episode of transient recovered pancytopenia in 2017. He is retired and lives with his wife. There is no alcohol or illicit drug consumption.

Upon admission, the patient's temperature was $39^{\circ} \mathrm{C}$, blood pressure was $108 / 83 \mathrm{mmHg}$, heart rate was 58 bmp and oxygen saturation was $93 \%$ on room air. He was alert but confused. Heart sounds were regular without any rubs or murmurs. Breath sounds were diminished in the right pulmonary base where rales were noted. The cutaneous examination revealed a painless non-infiltrative petechial purpura on the lower limbs.

Leucocytes were $1.7 \times 10^{9} / \mathrm{l}$, lymphocytes were $0.95 \times 10^{9} / \mathrm{l}$, haemoglobin was $14 \mathrm{~g} / \mathrm{dl}$, and platelets were $48 \times 10^{9} / \mathrm{l}$. CRP was $36.5 \mathrm{mg} / \mathrm{l}$. Electrolytes, renal function tests, and prothrombin time were within the normal range. Arterial blood gases (room air) revealed: $\mathrm{pH}$ : 7.45, $\mathrm{pCO}_{2:} 39 \mathrm{mmHg}, \mathrm{pO}_{2}: 73 \mathrm{mmHg}$ and $\mathrm{HCO}_{3}: 25.5 \mathrm{mmol} / \mathrm{I}$. The RT-PCR assay on oropharyngeal swabs for SARS-CoV-2 was positive. The chest scan was consistent with COVID-19 infection-related pneumonia. On day 2 , the platelet count was $46 \times 10^{9} / \mathrm{I}$ and leucocytes were $0.9 \times 10^{9} / \mathrm{I}$, and the cutaneous purpura was stable without any active bleeding. The platelet count had increased to $72 \times 10^{\circ} / /$ by day 5 and normalized on day 8.

\section{DISCUSSION}

The clinical spectrum in COVID-19-infected patients varies from mild to critical even though most infections are not severe. Patients presenting initially with mild symptoms may rapidly worsen over the course of a week. Acute respiratory distress syndrome (ARDS) is the most important serious complication and can develop shortly after the onset of dyspnoea. However, other complications such as arrhythmias, acute cardiac damage and shock have been reported in the literature. 
During SARS-CoV-2 infection, white blood count and coagulation disturbances have been reported, particularly in the form of lymphopenia and thrombocytopenia. These thrombocytopenias are usually moderate $\left(>100 \times 10^{9} /\right.$ I) except in patients with multi-organ failure with ARDS or capillary leak syndrome $\left(>50 \times 10^{9} /\right)^{[1]}$.

The patients described above developed sudden and potentially life-threatening thrombocytopenia. The usual causes of secondary and primary thrombocytopenia were eliminated. The diagnosis of immune thrombocytopenia was retained based on clinical and biological findings according to the consensus of the American Society of Hematology (ASH) ${ }^{[2]}$. However, it is important to highlight that immune thrombocytopenia remains a diagnosis of exclusion and that in the context of the coronavirus, other causes of thrombocytopenia such as antiphospholipid syndrome ${ }^{[3]}$ and thrombotic microangiopathy must be considered.

The severity of thrombocytopenia led us to consider immediate intravenous immunoglobulinadministration and eltrombopag. Treatment with hydroxychloroquine was discussed, in view of its potential effectiveness in patients with SARS-CoV-2 ${ }^{[4]}$ and immune thrombocytopenias ${ }^{[5]}$, but in the end was not considered.

In patients infected with COVID-19, the mechanisms leading to thrombocytopenia seem to be multifactorial: direct infection of bone marrow cells leading to abnormal haematopoiesis, or an autoimmune response against blood cells ${ }^{[1,6]}$. In addition, as patients develop ARDS, platelet count could decrease as the lung is an important site of platelet release from fully mature megakaryocytes, a process impaired by ARDS [7]. Treatment options for this entity have evolved and current protocols include rituximab, thrombopoietin receptor agonists (eltrombopag, avatrombopag, romiplostim), and high-dose dexamethasone as an alternative to prednisone ${ }^{[4]}$. Corticosteroids are the standard initial treatment for adults with immune thrombocytopenia who need treatment if there is no contraindication. The use of IVIg ( $1 \mathrm{~g} / \mathrm{kg}$ on $1 \mathrm{or} 2$ consecutive days or $0.4 \mathrm{~g} / \mathrm{kg}$ per day for 5 days) or intravenous anti-D (50-75 mg/kg once) where available, may be appropriate in patients with bleeding, or at high risk for bleeding, who are unresponsive to predniso(lo)ne. If anti-D is used, consideration must be given to potential triggering of DIC or haemolysis ${ }^{[8]}$. The use of platelet growth factors should be carefully evaluated taking into account the potential thrombotic events during coronavirus infection. Platelet transfusion is reserved for refractory visceral or cerebral meningeal haemorrhage. In conclusion, severe and life-threatening thrombocytopenia may be encountered in the course of COVID-19 infection. Treatment with intravenous immunoglobulins or thrombopoietin receptor agonists has been shown to be effective.

\section{REFERENCES}

1. Lippi G, Plebani M, Henry BM. Thrombocytopenia is associated with severe coronavirus disease 2019 (COVID-19) infections: a meta-analysis. Clin Chim Acta 2020;506:145148.

2. Neunert C, Terrell DR, Arnold DM, Buchanan G, Cines DB, Cooper N, et al. American Society of Hematology 2019 guidelines for immune thrombocytopenia. Blood Adv 2019;3:3829-3866.

3. Zhang Y, Xiao M, Zhang S, Xia P, Cao W. Coagulopathy and antiphospholipid antibodies in patients with Covid-19. N Engl J Med 2020;382(17):e38.

4. Gautret P, Lagier JC, Parola P, Hoang VT, Meddeb L, Mailhe M, et al. Hydroxychloroquine and azithromycin as a treatment of COVID-19: results of an open-label non-randomized clinical trial. Int J Antimicrob Agents 2020;20:105949.

5. Audia S, Godeau B, Bonnotte B. Is there still a place for "old therapies" in the management of immune thrombocytopenia? Rev Med Interne 2016;37:43-49.

6. Jolicoeur P, Lamontagne L. Impairment of bone marrow pre-B and B cells in MHV3 chronically-infected mice. Adv Exp Med Biol 1995;380:193-195.

7. Yang M, Ng MH, Li CK. Thrombocytopenia in patients with severe acute respiratory syndrome (review). Hematology 2005;10:101-105.

8. Provan D, Arnold DM, Bussel JB, Chong BH, Cooper N, Gernsheimer T, et al. Updated international consensus report on the investigation and management of primary immune thrombocytopenia. Blood Adv 2019;3:3780-3817. 